\title{
Tsafon
}

Revue d'études juives du Nord

$77 \mid 2019$

Contribution à l'histoire des traductions juives de la Bible hébraïque

\section{Journal de guerre (1939-1943) suivi de Journal d'un travailleur forcé et autres textes de circonstance}

\section{Emmanuel Persyn}

\section{(2) OpenEdition}

\section{Journals}

Édition électronique

URL : https://journals.openedition.org/tsafon/2104

DOI : $10.4000 /$ tsafon. 2104

ISSN : 2609-6420

Éditeur

Association Jean-Marie Delmaire

Édition imprimée

Date de publication : 1 septembre 2019

Pagination : 172-173

ISSN : $1149-6630$

\section{Référence électronique}

Emmanuel Persyn, « Journal de guerre (1939-1943) suivi de Journal d'un travailleur forcé et autres textes de circonstance », Tsafon [En ligne], 77 | 2019, mis en ligne le 09 septembre 2019, consulté le 24 juin 2021. URL : http://journals.openedition.org/tsafon/2104; DOI : https://doi.org/10.4000/tsafon. 2104

Ce document a été généré automatiquement le 24 juin 2021.

Tsafon. Revues d'études juives du Nord 


\title{
Journal de guerre (1939-1943) suivi de Journal d'un travailleur forcé et autres textes de circonstance
}

\author{
Emmanuel Persyn
}

\section{RÉFÉRENCE}

Paris, CNRS, 304 p., $10 €$

1 Édité et annoté par Guy Dugas, cet ouvrage réunit plusieurs écrits de l'écrivain et essayiste tunisien Albert Memmi : son Journal de guerre, écrit de 1939 à 1943, le Journal d'un travailleur forcé et, pour terminer, d'autres textes de circonstance. Au terme d'un travail remarquable, Guy Dugas a reconstitué ces articles d'une ou plusieurs pages manuscrites, dont certaines s'avèrent une suite de fragments, voire de très courtes annotations.

2 Qu'elles soient ou non développées, ces pages précisent l'attitude d'Albert Memmi durant la Seconde Guerre mondiale. Il n'est alors qu'un jeune homme, à peine âgé de 19 ans, davantage préoccupé, écrit Guy Dugas, «...par ses études, ses tenues vestimentaires, la fréquentation de la gent féminine et le militantisme juif que par les événements qui ont commencé à secouer l'Europe». Le 3 septembre 1939, Albert Memmi écrit ainsi : «Je suis contre la guerre, je tiens nullement à la faire. Je n'irai que si j'y étais obligé ».

3 Il réfléchit, mûrit, prend néanmoins parti lorsqu'il perçoit clairement la dimension antisémite des événements. Ainsi, le 24 juin 1940, écrit-il: "C'est curieux, après beaucoup d'appels à la modernité, beaucoup de raisonnements que je m'impose, beaucoup de la résignation, où je me dis qu'il vaut mieux accepter, céder, etc., combien je sens en moi rejaillir la révolte ». Une révolte née de ce que « ...je porte le poids d'être juif ». Et de préciser un peu plus loin : «Le Juif ne crée pas l'antisémitisme par sa façon de faire; son existence crée l'antisémitisme ». Au fil des pages de son journal, il 
dénonce vigoureusement l'antisémitisme des dirigeants allemands, italiens et français. "L'antisémitisme est tellement fort, tellement grandissant que je commence à douter de tout ", écrit-il par exemple le 26 mai 1941.

Albert Memmi s'oppose plus nettement encore lorsque les troupes allemandes arrivent en Tunisie. Pourtant, les jeunes Tunisiens ne s'inquiètent pas plus que cela à l'arrivée des troupes allemandes. "Nous n'avions pas réalisé absolument le péril allemand. En réalité, il y avait autre chose : pour tous, les Allemands ne tiendraient pas en Tunisie ; leur séjour ne durerait que quelques jours", écrit Albert Memmi dans un article intitulé "La Question des camps de travail en Tunisie ", qui reprend une constatation émise à plusieurs reprises ailleurs dans l'ouvrage.

Cruelle désillusion! L'armée allemande occupe la Tunisie durant sept mois. Sept mois durant lesquels le régime nazi s'en prend à la communauté juive comme il l'a fait dans les autres pays passés sous sa botte. Il est à peine installé qu'il exige, le 6 décembre 1942, des responsables de la communauté juive une liste nominative de mille personnes puis de trois mille... Quelques jours plus tard, il ordonne une première rafle, avec le concours de la police de Vichy, puis les premiers internements. Dans l'article intitulé "Les Juifs de Tunisie pendant l'occupation allemande », Albert Memmi rappelle avec vigueur « ...cette pénible aventure que certains imbéciles ont baptisée 'collaboration' ». Et d'ajouter : « Nous n'avons de leçon à recevoir de personne ».

En Tunisie comme ailleurs, l'attitude des responsables de la communauté juive soulève « ...un certain nombre de problèmes qui, comme tous ceux qui engagent des hommes, sont noyés dans des flots de passion ", note Albert Memmi. Selon lui, la résistance armée était vaine car condamnée d'avance et le refus de fournir des travailleurs aux autorités allemandes « ...aurait abouti à un pogrom général » sans pour autant mettre fin aux demandes de main-d'œuvre de l'occupant. «En acceptant sans lutte ouverte le service du travail obligatoire, les Juifs ont pu limiter les dégâts ; et c'est au fond ce qui importait car le refus total était une pure chimère et peu habile, malgré les apparences ", résume-t-il.

7 Cette tâche est dévolue au "Comité de recrutement de la main-d'œuvre juive ", un organisme qui est distinct des institutions communautaires traditionnelles et qu'Albert Memmi décrit et défend dans deux articles repris dans cet ouvrage, non sans pointer qu' « ...il a sauvé de préférence une classe de la population : les fils de notables », ce qui engendre des conflits entre les responsables opportunistes de ce comité et sa section dite bureau de recrutement, " chargé d'un travail qui ne pouvait le faire aimer ». Dans les camps, dès le 15 janvier 1943, "...commença une besogne patiente et tenace de désorganisation qui produisit d'excellents résultats ", raconte Albert Memmi puisque "...les délégués de la communauté réussirent à vider presque complètement les camps ».

Et, parce que la communauté juive a fait ce choix, écrit Albert Memmi, s'impose la relève des hommes envoyés dans les camps de travail. Le 20 mars 1943, il part pour le camp d'Aïn Hloua. "C'est le jour où j'ai compris toutes ces données du problème que moi, planqué pendant des mois, j'ai rejoint volontairement les camps de travail». "J'avais l'impression de m'enfoncer dans un gouffre sans fond. [...] Le sentiment de ne plus exister en tant que personnalité distincte, ou plus exactement de n'avoir aucune prise sur les événements », se souvient-il.

Volontaire, Albert Memmi n'en souffre pas moins de la faim, de la douleur physique, du manque d'hygiène, de la fatigue. Et plus que tout des brimades constantes, de 
l'humiliation, de l'antisémitisme. À la lutte permanente pour la simple survie s'ajoute le combat obstiné pour la dignité, l'illustration du judaïsme. Guy Dugas intitule très justement son introduction «Les trois guerres d'Albert Memmi » : rappelant sa vie dans un camp de travail, son combat contre l'antisémitisme et son engagement contre le colonialisme, il voit dans cet ensemble d'écrits « ...un véritable document historique ». 